\title{
Research Paper: Relationship Between Lifestyle and Social Vitality of Women Over 18 Years Old Living in Sanandaj City, Iran
}

\author{
Yaghoub Ahmadi ${ }^{*}$ (1) \\ 1. Department of Sociology, Faculty of Social Sciences, Sanandaj Branch, Payam-noor University, Iran.
}

Citation Ahmadi Y. Relationship Between Lifestyle and Social Vitality of Women Over 18 Years Old Living in Sanandaj City, Iran. Journal of Research \& Health. 2020; 10(4):201-206. http://dx.doi.org/10.32598/JRH.10.4.1506.1

http://dx.doi.org/10.32598/JRH.10.4.1506.1

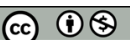

Article info:

Received: 14 Feb 2018

Accepted: 12 Jun 2018

Publish: 01 Jul 2020

\section{Keywords:}

Lifestyle, Health, Happiness, Women, Selfactualization

\begin{abstract}
A B S T R ACT
Background: Vitality and happiness are one of the important components of social welfare affecting individuals' efficiency and quality of life. Lifestyle variations, especially the type of health-oriented lifestyle, are important determinants of social happiness. According to this, the aim of this study was to investigate the relationship between lifestyle and social happiness of women over 18 years in Sanandaj in 2017-2018.

Methods: The method of this study was descriptive type of correlational. The statistical population consisted of women over 18 years in Sanandaj. The sample size was 380 based on the Cochran formula and were selected by multi-stage cluster sampling. The research's tool was a combination of Walker's Standard Questionnaire and researcher-made questionnaire.

Results: The Pearson correlation and regression analysis were used to analyze the data by SPSS 22 software. Descriptive results indicated that dimensions of healthy life-style (spiritual growth and Self-actualization, responsibility about health, interpersonal relationships and nutrition, exercise and physical activity, and stress management) caused $37 \%$ of changes in the happiness among women of Sanandaj. In addition, the effect of interpersonal relationships has been more than the others.

Conclusion: Based on findings, it can be concluded that choosing a healthy lifestyle will lead to increase happiness among women and in this field, the role of interpersonal relationship as one of lifestyle indicators for happiness is more determinative and important so it would be worthy of attention to the cultural, medical and even educational centers of Iran.
\end{abstract}

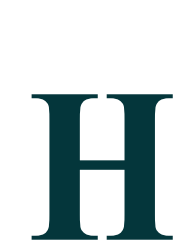

\section{Introduction}

appiness is one of the main dimensions of human experience and usually seeks to create satisfactory responses that provide proper function [1]. Research about happiness has not been guided by theory. Although particular findings can be explained by a single theory, some of them may need more than one theory [2]. Argyle analyzed happiness understanding with three components: A high level of satis-

\section{* Corresponding Author:}

Yaghoub Ahmadi, PhD.

Address: Department of Sociology, Faculty of Social Sciences, Sanandaj Branch, Payam-noor University, Iran.

Phone: +98 (918) 1737395

E-mail:yahmady2001@yahoo.com 
faction at most times, having a positive excitement, and a relative lack of negative emotions. By developing a theory of equality, Adams stated that the occurrence of fair behaviors in different domains was effective in increasing calmness and leads to happiness in societies [3].

Ted Garr in the theory of relative deprivation proposed the idea that comparison is the main factor in an individual's satisfaction or dissatisfaction, as well as happiness and vitality. Generally, human beings compare themselves to others and when they feel a sense of poverty and inferiority, they show intensive emotional reactions such as job switching, sabotage, suicide, and so on. Also, when that feeling reaches out to the extreme, it will lead both to a sense of social and extreme conflicts. In general, according to the relative deprivation perspective, if people compare themselves with the other members of the reference group and finds that based on their investments and efforts, the reward and the result are not fair and equitable, they develop a sense of relative deprivation that causes dissatisfaction and a sense of boredom, or lack of vitality, at the two individual and social levels [4].

Seligman suggested that there are three sources for happiness: luscious life, attachment of life, and purposeful work. The first two of them are optional and depend on the individual's perception of events, but the third one, according to Seligman, means doing things to accept of values and aiming beyond the satisfaction of individual tendencies. Based on Seligman's view, real happiness comes when someone has achieved these three sources of happiness [5]. With the proposition of value attainment idea, Darling and Steinberg believed that vitality is not a personal feeling, but a fact that is independent on the individual sentiments, namely the attainment of things that are generally considered to be valuable [6]. Additionally, Argyle argues that one of the ways to increase happiness and possibly the best of it is to increase happiness through a change in lifestyle.

The concept of lifestyle is one of the most important social meanings that entered sociological literature in the 1920s. The scope and domain of the lifestyle concept have not been an endless controversy among social sciences theorists. Some have attempted to classify the concept as the subset of a social class to get richness and dynamism to class, but in contrast, many have considered lifestyle to be conceptual across class and beyond class divisions. In the literature of sociology, there are two conceptualizations of the concept of lifestyle. One related to the 1920s, whose lifestyle reflects the wealth and social status of individuals, and is often used as an indicator of social class determination, and secondly, as a new social form, meaning only in the context of the changes in modernity and the growth of consumerism culture. In this sense, lifestyle is a way of defining the values, attitudes, and behaviors of individuals that increase their significance for social analysis on an ongoing basis [7].

Lifestyle is a way that people choose throughout their lives and are built on in the family, which is influenced by culture, race, religion, socio-economic status, and beliefs [8]. In other words, lifestyle is a relatively coherent set of all behaviors and activities of a particular person in the course of daily life [9]. Today, a type of lifestyle has been more important, which is all in line with health and happiness and is considered as a health-oriented or a healthy lifestyle. Cocerham, a healthy lifestyle theorist, believes that a healthy lifestyle is a set of choices that a person chooses based on his social status, and these choices derive from the structural situation and his position. The opportunities of a person's life are determined by the social status and characteristics of the specially designated groups. He considers the following items as components of a healthy lifestyle index; food consumption, exercise, personal hygiene, stress management, smoking, alcohol and drug use, seat belts, brushing, and medical examinations [10].

Denis Raphael is another healthy lifestyle thinker who believes in a study of the status of health and effective factors, based on social determinative approach. In the healthy lifestyle model, the disease is found in nonhealthy choices such as a diet lacking fruits and vegetables, inactivity, alcohol and tobacco consumption. Treatment for poor choices requires health education, encouraging individuals to change their behavior, and even environmental constraints and social controls, such as taking fine, banning smoking and alcohol to make healthy choices and easy choices [11].

A healthy lifestyle is one of the new subsets of lifestyle that has recently drawn the attention of researchers and thinkers because of its positive effects. A healthy lifestyle aims to promote healthy behaviors and prevent high-risk behaviors. Attention to lifestyle and health means that by changing the mental and behavioral aspects, the person's health is guaranteed and can be promoted. From this perspective, choosing the type of healthy lifestyle can provide one of the prerequisites for social happiness and vitality in Iranian society, especially in Kurdistan Province. Hence, this article attempts to answer the question of what is the situation of the women's happiness in different dimensions (emotional, cognitive, and social) in Sanandaj City, Iran, and how much the choice of healthy lifestyle impacts the happiness of women in this city. 


\section{Methods}

This is a cross-sectional study which in terms of control of research conditions is a survey. The study population comprised women over 18 years old living in Sanandaj. The sample size was 380 based on the Cochran formula with the maximum distribution of traits ( $\mathrm{p}$ and $\mathrm{q}$ of both $0.5)$ and a probability of $95 \%(\mathrm{P}=0.05)$. To attain a representative sample, based on cluster sampling, three clusters that were representative of the economic and social status have been selected from three different levels in Sanandaj. The research unit is individual and the domain is the first six months of research year (2017-2018).

The data gathering tool was a standardized and researcher-made questionnaire that had good reliability and validity. To assess the validity of the questionnaire, the face validity was used and the Cronbach alpha was used to measure its reliability (Table 1).

\section{Healthy lifestyle}

In this study, a healthy lifestyle was assessed by lifestyle improvement of health promotion. This profile is based on health promotion patterns and measures the likelihood of a person engaging in health-promoting behaviors. The new version is an elaborate form that has been developed by Walker and colleagues and measures the lifestyle of improving health by focusing on the innovative work of the individual who acts to maintain or increase his or her wellbeing, self-actualization, and individual self-esteem. The questionnaire comprised six sub-categories of nutrition, exercise, and physical activity, health responsibility, stress management, interpersonal relations, and spiritual growth. Respondents were asked to rate on a 4-point Likert response (never, 1; sometimes, 2; often, 3; and typically,4) to determine how much health promotion behaviors they do.

\section{Happiness:}

In this study, happiness was assessed based on three dimensions of social, cognitive, and emotional, and the items are rated on a 5-point Likert scale. There are 6 items for the social dimension, 11 items for the emotional dimension, and 12 items for the cognitive dimension. Based on this, the minimum happiness score is 30 and the maximum is 150 . The minimum indicates a low level of happiness and a maximum of a high level of it.

\section{Results}

The research findings are presented in two sections. In the first part, descriptive indexes of various dimensions of a healthy lifestyle and happiness are presented. In the second part, research hypotheses about the effect of a healthy lifestyle, and its dimensions on happiness are reviewed.

According to table 2, the level of spiritual growth and self-actualization, responsibility for health, and interpersonal relationships of women are at a modest level. Also, the level of stress management and exercise and physical activity of women are lower than the average and the level of attention to nutrition by them is moderate.

Table 1. The reliability of the indicators based on the Cronbach alpha coefficient

\begin{tabular}{|c|c|c|c|}
\hline Index & Dimensions & $\begin{array}{l}\text { Number of } \\
\text { Items }\end{array}$ & $\begin{array}{l}\text { The Reliability of Dimensions } \\
\text { and Indicators }\end{array}$ \\
\hline \multirow{7}{*}{ Healthy lifestyle } & Spiritual growth and self-actualization & 6 & 0.728 \\
\hline & Responsibility about health & 6 & 0.794 \\
\hline & Interpersonal relationships & 6 & 0.701 \\
\hline & Exercise and physical activity & 5 & 0.821 \\
\hline & Stress management & 5 & 0.711 \\
\hline & Nutrition & 6 & 0.789 \\
\hline & Total & 34 & 0.914 \\
\hline \multirow{4}{*}{ Happiness } & Emotional dimension & 11 & 0.845 \\
\hline & Social dimension & 6 & 0.785 \\
\hline & Cognitive dimension & 12 & 0.912 \\
\hline & Total & 29 & 0.923 \\
\hline
\end{tabular}

The Pearson correlation and regression analysis were used for analyzing the data in SPSS V. 22. 
The results of this study about research variables indicate a significant and direct relationship between the status of a healthy lifestyle and its dimensions and happiness of the respondents. The intensity of this relationship in the healthy lifestyle index is high (0.546) and among dimensions, the highest intensity is related to the interpersonal relationship variable (0.524). In this regard, the age of respondents had no significant effect on happiness (Table 3 ).

Based on the multivariate linear regression test and by using a step-by-step method to explain happiness through the sum of independent variables, the coefficient of multiple correlations (R) is 0.612 and the coefficient of explanation of the equation is equal to 0.375 , which shows that $37 \%$ of happiness variable is explained by components of a healthy lifestyle. Also, the results of the analysis in the fit model of happiness according to the obtained F-value $(\mathrm{F}=63.243$, Sig. $<0.001)$ showed that the corrected AR model was significant.

In addition, among the variables, the dependent variable is more effective than the interpersonal relationships among the dimensions of a healthy lifestyle. In other words, the management of interpersonal relationships explains $22 \%$ of the variations of the dependent variable (Table 4).

\section{Discussion}

In general, the results of this study showed a significant correlation between a healthy with happiness and its dimensions.

In this research, happiness was divided into three dimensions (emotional, cognitive, and social) to analyze the happiness variable. In conclusion, the average di-

Table 2. The main study variables

\begin{tabular}{|c|c|c|c|c|}
\hline Variable & Mean $\pm S D$ & Min. & Max. & No. \\
\hline Happiness & $63.08 \pm 15.41$ & 29 & 145 & 374 \\
\hline Emotional later & $30.11 \pm 6.327$ & 11 & 55 & 378 \\
\hline Cognitive dimension & $31.07 \pm 7.08$ & 12 & 60 & 375 \\
\hline Social dimension & $18.03 \pm 4.95$ & 6 & 30 & 375 \\
\hline Healthy lifestyle & $78.24 \pm 14.34$ & 34 & 170 & 375 \\
\hline Spiritual growth and self-actualization & $18.23 \pm 3.64$ & 6 & 24 & 375 \\
\hline Health Responsibility & $15.58 \pm 3.64$ & 6 & 32 & 375 \\
\hline Interpersonal relationships & $17.35 \pm 3.11$ & 6 & 28 & 375 \\
\hline Stress management & $10.08 \pm 2.34$ & 5 & 16 & 375 \\
\hline Exercise and physical activity & $12.43 \pm 3.97$ & 5 & 20 & 375 \\
\hline Nutrition & $15.74 \pm 4.124$ & 6 & 24 & 375 \\
\hline
\end{tabular}

Table 3. Testing of assumptions and correlations of research variables

\begin{tabular}{|ccc|}
\hline \multirow{2}{*}{ Variable } & \multicolumn{2}{c}{ Happiness } \\
\cline { 2 - 3 } & Correlation Coefficients & Significance Level \\
\hline Healthy lifestyle & 0.546 & $>0.001$ \\
\hline Spiritual growth and self-actualization & 0.411 & $>0.001$ \\
\hline Health responsibility & 0.394 & $>0.001$ \\
\hline Interpersonal relationships & 0.524 & $>0.001$ \\
\hline Stress management & 0.287 & $>0.001$ \\
\hline Exercise and physical activity & 0.414 & $>0.001$ \\
\hline Nutrition & 0.176 & $>0.001$ \\
\hline Age & 0.097 & $>0.008$ \\
\hline Education & 0.124 & $>0.001$ \\
\hline
\end{tabular}


Table 4. Statistics for independent variables remaining in the model

\begin{tabular}{cccccc}
\hline Variable & B & STD.B & Beta & T & P \\
\hline Y-intercept & 78.112 & 6.57 & - & 12.532 & $<0.001$ \\
\hline Interpersonal relationships & 0.645 & 0.193 & 0.227 & 4.841 & $<0.001$ \\
\hline Spiritual growth and self-actualization & 0.432 & 0.121 & 0.173 & 4.763 & $<0.001$ \\
\hline Health responsibility & 0.346 & 0.113 & 0.147 & 3.528 & $<0.001$ \\
\hline Exercise and physical activity & 0.462 & 0.184 & 0.213 & 5.812 & $<0.001$ \\
\hline Stress management & 0.375 & 0.117 & 0.176 & 2.946 & $<0.001$ \\
\hline Nutrition & 0.211 & 0.108 & 0.134 & 3.124 & $<0.001$ \\
\hline
\end{tabular}

unt

mensions of happiness are located in the lower range in all three dimensions. Also, the happiness index is at a low level. The healthy lifestyle model was measured with six dimensions to analyze the healthy lifestyle variable in this research. So, the highest mean was related to interpersonal relationships and self-actualization and exercise. Besides, the analytical results of the research indicated a significant and direct relationship between the healthy lifestyle and its dimensions with the happiness index. On the other hand, the results of multiple regression analysis showed that interpersonal relationships, exercise, and physical activity highly affect happiness variables. It seems that increasing the level of interpersonal relationships would improve the level of women's happiness and also exercise is an important factor which plays a vital role in the promotion of happiness among women.

\section{Conclusion}

The results of this study are based on the effect of a healthy lifestyle on happiness which agrees with the research of Ghomri, [12], Steffani Korff [13], and Bourne et al. [14]. In general, the results of this study confirm the Weber and Bourdieu's view about the impact of a healthy lifestyle [15] on the status of activity in the contemporary era. Lastly, the results of the research indicated no positive and significant relationship between age and happiness, and education has had positive effects on the happiness of the respondents. Concerning the educational variable, this study is consistent with the findings of Diner and colleagues [16]. It seems that the role of education can be considered in creating wider interests and inner satisfaction which provides more sources of happiness.

\section{Ethical Considerations}

\section{Compliance with ethical guidelines}

The study was ethically approved and registered under license No. S/7/8053 historian December 10, 2019.

\section{Funding}

This research did not receive any specific grant from funding agencies in the public, commercial, or non-profit sectors

\section{Acknowledgments}

The authors appreciate the support of the Payame Noor University of Sanandaj and the cooperation of all women who participated in this study.

\section{References}

[1] Seligman MEP, Schulman P, DeRubeis RJ, \& Hollon SD. The prevention of depression and anxiety. Prev Treat. 1999; 2(1):Article 8a. [DOI:10.1037/1522-3736.2.1.28a]

[2] Argyll M. Psychology of Happiness [A. Gohari, Persian trans]. Esfahan: Jihad University of Isfahan; 2003.

[3] Moradi M, Jafari SE, Abedi MR. [Happiness and personality: A review study (Persian)]. Adv Cogn Sci. 2005; 7(2):60-71.

[4] Fazlollahi S, Jahangir N, Haghgoyan Z. [Measuring the Effective Rates and Functions on Students' Happiness in Qom Campus, University of Tehran (Persian)]. J Psychol Relig. 2010; 4(4):81-108. https:/ /b2n.ir/790408

[5] Cockerham W. Sociology of health and health life styles. London: Prentice Hall College; 2000. 
[6] Darling N, Steinberg L. Parenting style as context: An integrative model. Psychol Bull. 1993; 113(3):487. [DOI:10.1037/00332909.113.3.487]

[7] Abazari Y, Chavoshyan H. [From Class to lifestyle: New approaches to sociological analysis of social identity (Persian)]. J Soc Sci Lett. 2002; 20(3):27-3. http://www.sid.ir/ FileServer/JF/50613812001

[8] Fazeli M. Consumption and lifestyle. Tehran: Sobh Sadegh Publishing; 2002

[9] Giddens A. The Consequences of Modernity (Solati M, Persian trans). Tehran: Markaz Publisher; 2000.

[10] Cockerham WC, Rütten A, Abel T. Conceptualizing contemporary health lifestyles: Moving beyond Weber. Sociol $\mathrm{Q}$. 1997; 38(2):321-42. [DOI:10.1111/j.1533-8525.1997.tb00480.x]

[11] Raphael, D. Social determinants of health: Canadian perspectives, 2nd edition. Toronto: Canadian Scholars' Press; 2009.

[12] Ghomri M. Study of relationship between religion and happiness among students by gender and marital status. J Psychol Relig. 2010; 1(11):75-91. www.ensani.ir/storage/ Files/20120328161655-2030-19.pdf

[13] Korff SC. [Religious orientation as a predictor of life satisfaction within the elderly population (English)]. [PhD. Thesis]. Minneapolis: Walden University; 2006.

[14] Bourne PA, Morris C, Eldemire-Shearer D. Re-testing theories on the correlations of health status, life satisfaction and happiness. N Am J Med Sci. 2010; 2(7):311.

[15] Azadarmaki T. Everyday life in Iran, everyday life, power, and culture. Tehran: University Jihad; 2006.

[16] Diener E, Seligman ME. Very happy people. Psychol Sci. 2002; 13(1):81-4. [DOI:10.1111/1467-9280.00415] [PMID] 